\title{
EDITORIAL
}

\section{Community Care for Older Adults- the Patient/Caregiver Perspective}

DOI:https://doi.org/10.5770/cgj.20.286

Our June 2017 issue focuses on a number of original research articles examining community care from the point of view of both patients and caregivers. Figueiredo et al ${ }^{(1)}$ demonstrate, using cross-sectional data, that simply asking older adults their self-reported health status can be suggestive of a need for further rehabilitation services. We also present the results of a CIHR-funded conference that used qualitative methods to examine the barriers and challenges to caregiver access of community supports. ${ }^{(2)}$ A qualitative study by Piraino et al., ${ }^{(3)}$ using both focus group and individual interviews, also examines the potential of online networks to assist in longstanding community-care issues such as communication and the sharing of information.

Enjoy!

Cheers,

Dr. Kenneth M. Madden, Colleen Maxwell and Mark Rapoport

Editorial Board

Canadian Geriatrics Journal

\section{REFERENCES}

1. Figueiredo S, Rozensveig A, Morais JA, Mayo N. Planning health services for seniors: can we use patient's own perception? CGJ. 2017;20(2):66-74.

2. Charles L, Brémault-Phillips S, Parmar J, Johnson M, Sacrey LA. Understanding how to support family caregivers of seniors with complex needs. CGJ. 2017;20(2):75-84.

3. Piraino E, Byrne K, Heckman GA, Stolee P. Caring in the information age: personal online networks to improve caregiver support. CGJ. 2017;20(2):85-93. 